\title{
FAKTOR YANG MEMPENGARUHI PRODUKSI USAHA MIKRO KECIL DAN MENENGAH (UMKM) PRODUK KERIPIK DI KOTA TARAKAN
}

\author{
Ali Lutfi Munirudin ${ }^{1}$, Elly Jumiaty ${ }^{2}$, Nurlela Machmuddin ${ }^{3}$ \\ ${ }_{1,2,3}$ Program Studi Agribisnis, Fakultas Pertanian, Universitas Borneo Tarakan, \\ Jl. Amal Lama no 1, Tarakan Timur, Tarakan. \\ E-Mail: lelamachmudin@gmail.com
}

Received : 7 Maret $2019 \quad$ Accepted : 18 April 2019

\begin{abstract}
Micro Small and Medium Enterprises (SMEs) in Tarakan City is potencially to be developed. One of SMEs many developed is the chips business. According to the data from the Department of Animal Husbandry and Food Crop of Tarakan City in 2016, there were 15 types of SMEs product of chips are scattered throughout the Tarakan city. To develop of SMEs, increasing the production of chips was needed. To reach the maximum level of chips production, the businessmen had to have a complete knowledge about chips production factors which are used. How far was the influence of the chips production inputs to the output. The appropriate production factors use with reaching the level production. This research aimed to (1) Know what factors influence the production of Micro, Small and Medium Enterprises (SMEs) Product of Chips in Tarakan, (2) determine the factors that most affect the production of Micro, Small and Medium Enterprises (SMEs) Product of Chips in Tarakan City. This research was conducted in Tarakan City. The samples which in the study is 15 units Micro, Small and Medium Enterprises (SMEs) which chips produce and the method of data analysis used is path analysis. Intend path analysis to determine the pattern of relationship independent variable $(\mathrm{X})$ which influencing dependent variable $(\mathrm{Y})$, to know the value of relationships and influence done several is Kolmogorov-smirnov test, correlation coefficient test, $\mathrm{F}$ test and $\mathrm{t}$ test. According to the results of research which was analyzed by using path analysis, we obtained that (R2) was 97,8 persen, means the ability of independent variable inside variance explained from dependent variable. Influencing factors in production were raw materials (X1), equipment (X2), Labor (X3). The influence of raw materials $(\mathrm{X} 1)$ to production $(\mathrm{Y})$ was 38,7 persen. The influence of equipment (X2) to production $(\mathrm{Y})$ was 3,7 persen. The influence of labor (X3) to production $(\mathrm{Y})$ was 55,3 persen. We could see that the most influential factor to the production of these chips business was the raw labor (X3) with the total effect was 55,3 persen.
\end{abstract}

Keywords: path analysis, product, SMEs

\begin{abstract}
ABSTRAK
Usaha Mikro, Kecil dan Menengah (UMKM) di Kota Tarakan sangat berpotensi dikembangkan, salah satu diantaranya adalah usaha keripik. Berdasarkan data Dinas Peternakan dan Tanaman Pangan Kota Tarakan 2016, terdapat 15 jenis UMKM produk keripik yang tersebar di seluruh wilayah Kota Tarakan. Untuk pengembangan UMKM ini perlu adanya peningkatan produksi keripik. Untuk mencapai tingkat produksi keripik yang maksimum, pelaku usah harus memiliki pengetahuan yang lengkap atas faktor-faktor produksi keripik yang digunakannya. Sejauh mana pengaruh input produksi keripik terhadap output yang dihasilkan, Tujuan penelitian ini adalah menfaktor apa saja yang mempengaruhi produksi UMKM pada usaha keripik di Kota Tarakan, dan mengetahui faktor yang paling berpengaruh terhadap produksi Usaha Mikro Kecil dan Menengah (UMKM) produk keripik di Kota Tarakan. Sampel yang digunakan dalam penelitian ini adalah 15 unit UMKM yang memproduksi keripik dan metode analisis data yang digunakan adalah analisis jalur. Analisis jalur bertujuan untuk mengetahui pola hubungan variable bebas $(\mathrm{X})$ yang mempengaruhi variable terikat (Y), untuk mengetahui besarnya nilai hubungan dan pengaruhnya dilakukan dengan beberapa cara yaitu uji normalitas, uji koefisien korelasi, uji $\mathrm{F}$ dan uji t. Berdasarkan hasil penelitian yang di analisis menggunakan analisis jalur, diperoleh (R2) sebesar 97,8 persen artinya kemampuan variabel bebas dalam menjelaskan varian dari variabel terikat adalah sebesar 97,8 persen. Faktor yang berpengaruh dalam produksi keripik adalah bahan baku (X1) sebesar 38.7 persen, peralatan (X2) 3.7 persen dan tenaga kerja (X3) sebesar 55.3 persen. Dapat kita lihat bahwa faktor yang paling berpengaruh dalam produksi keripik ini adalah tenaga kerja (X3) dengan total pengaruh sebesar 55.3 persen.
\end{abstract}

Kata kunci: analisis jalur, produk, UMKM. 


\section{PENDAHULUAN}

Peran usaha mikro, kecil dan menengah (UMKM) dalam perekonomian kota Tarakan cukup besar diantaranya dapat mengurangi pengangguran dan dapat meningkatkan pendapatan pelaku usaha kemudian akan berimplikasi pada perekonomian kota Tarakan. Berdasarkan data pusat statistika Tarakan menunjukan bahwa UMKM dari tahun 2015 meningkat dibandingkan tahun 2014. Jumlah UMKM pada tahun 2014 terdapat 536 unit sedangkan tahun 2015 terdapat sebanyak 563 unit. Peningkatan ini menjadi bukti bahwa perkembangan UMKM di kota Tarakan dan mempunyai peranan strategis dalam perekonomian kota Tarakan. Selain karena jumlahnya yang cukup banyak UMKM ini memnjadi prosopek yang baik untuk di tingkatkan.

Saat ini banyak berkembang usaha mikro terutama terkait dengan usaha pengolahan makanan olahan hasil pertanian. Produk hasil pertanian yang diolah terdapat nilai tambah yang cukup tinggi ketika diolah menjadi produk, selain itu harga dari hasil pertanian yang cukup terjangkau, dilihat dari ketahanan hasil pertanian ini tidak dapat bertahan dalam waktu yang lama sehingga di butuhkan pengolahan hasil pertanian menjadi produk lain yang dapat bertahan lama dan karena dianggap mudah dalam proses pengolahannya. Berdasarkan data Dinas Peternakan dan Tanaman Pangan Kota Tarakan 2016 , terdapat 47 jenis UMKM yang tersebar di seluruh wilayah Kota Tarakan mengolah bahan makan dari hasil pertanian. Jenis usaha makanam yang mudah dalam pengolahannya adalah jenis makanan ringan, 15 diantara UMKM yang ada di Kota Tarakan adalah UMKM yang mengolah makanan ringan adalah produk keripik. Usaha pengolahan keripik termasuk dalam industri hasil pertanian.

Industri keripik di Tarakan dalam proses produksinya menggunakan faktor-faktor produksi yang beraneka ragam, baik yang bersifat permanen (tetap) maupun non permanen (variabel). Sumber bahan baku utama industri ini didapat dari alam dan berasal dari wilayah sekitar dan ada beberapa dari wilayah kota Tarakan, sehingga mengalami sedikit kesulitan dalam mendapatkan bahan baku yang sesuai dengan kebutuhan. Peralatan yang digunakan dalam proses produksi yang masih rendah sehingga mempengaruhi tingkat produksi ditambah lagi penggunaan tenaga kerja yang belum maksimal.
Untuk mencapai tingkat produksi keripik yang maksimum, pelaku usaha harus memiliki pengetahuan yang lengkap atas faktor- faktor produksi keripik yang digunakannya. Sejauhmana pengaruh input produksi keripik terhadap output yang dihasilkan, penggunaan faktor produksi keripik yang tepat akan tercapainya tingkat produksi. Menyadari hal tersebut, maka peningkatan produksi yang di dukung oleh tingkat teknologi dan penggunaan tenaga kerja yang efisien dan efektif diharapkan dapat meningkatkan keuntungan UMKM. Berdasarkan latara belakang tersebut maka dalam penelitian ini akan dikaji mengenai pengaruh penggunaan faktor-faktor produksi terhadap produksi kesripik di UMKM. Adapun tujuan yang ingin dicapai dalam penelitian adalah menganalisis dan mengidentifikasi faktorfaktor apa saja yang mempengaruhi produksi produk keripik pada Usaha Mikro Kecil dan Menenga (UMKM) di Kota Tarakan.

\section{Lokasi dan Waktu Penelitian}

Penelitian ini dilaksanakan di Kota Tarakan. Sampel dalam penelitian ini adalah UMKM yang memproduksi keripik. Metode penentuan sampel dilakukan secara sensus yaitu memilih semua UMKM di Kota Tarakan yang memproduksi keripik sehingga jumlah sampel adalah 15 UMKM.

Data yang digunakan dalam penelitian ini adalah data primer dan data sekunder. Data primer diperoleh dari UMK melalui pengamatan dan wawancara secara langsung menggunakan kuesioner yang telah disiapkan. Data sekunder diperoleh dari instansi dan dinas terkait, seperti Badan Pusat Statistik (BPS), Perpustakaan LSI IPB, artikel, jurnal, buku, literatur internet, dan berbagai sumber lain yang berkaitan dengan penelitian ini.

\section{Analisis Data}

Perhitungan analisis data kuantitatif menggunakan komputer dengan menggunakan software SPSS. Pada penelitian ini analisis jalur digunakan yaitu untuk menganalisis faktorfaktor yang mempengaruhi produksi UMKM produk kripik di Kota Tarakan. Perhitungan analisis data kuantitatif menggunakan komputer dengan menggunakan software SPSS. Model penelitian yang dapat dijadikan pedoman analisis jalur adalah : 


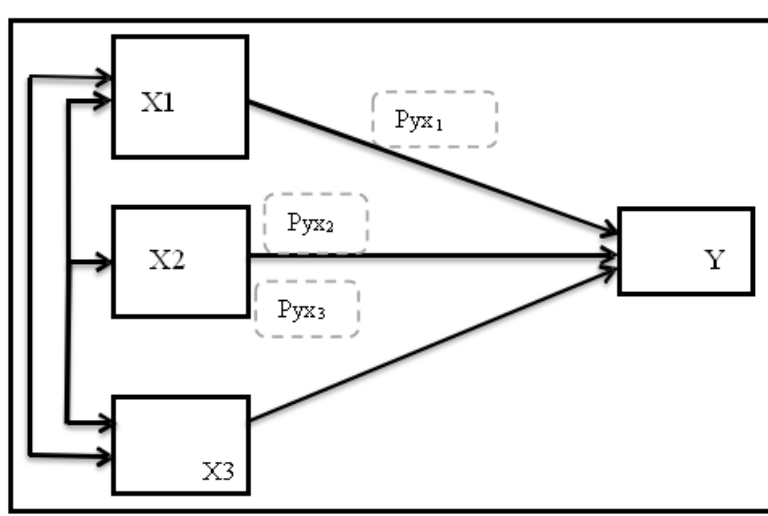

Gambar 1. Bagan Analisis Jalur

Dari Gambar. 1. Bahwa diagram jalur berisi tiga buah variabel eksogenus $\mathrm{X} 1 \mathrm{X} 2$ $\mathrm{X} 3$, dan sebuah variabel endogenus Y, persamaan untuk diagram jalur adalah:

$\mathrm{Y}=$ Pyx $1 X 1+$ Pyx $2 X 2+$ Pyx $3 X 3+$ e...pers (1)

Keterangan :

$\mathrm{X} 1=$ Bahan Baku

$\mathrm{X} 2=$ Peralatan

$\mathrm{X} 3=$ Tenaga Kerja

$\mathrm{y}=$ Produksi

Pyx1,Pyx2, Pyx3 = koefisien-koefisien jalur

$\mathrm{X} 1, \mathrm{X} 2, \mathrm{X} 3=$ Variabel bahan baku (X1), variabel peralatan (X2), variabel tenaga kerja (X3) menggambarkan besarnya pengaruh langsung terhadap produksi (Y).

$\mathrm{X} 1, \mathrm{X} 2=$ Variabel bahan baku (X1), variabel peralatan (X2) menggambarkan besarnya pengaruh X1 melalui hubungan X2 terhadap produksi (Y).

$\mathrm{X} 1, \mathrm{X} 3$ = Variabel bahan baku (X1), variabel tenaga kerja (X3) menggambarkan besarnya pengaruh $\mathrm{X} 1$ melalui hubungan $\mathrm{X} 3$ terhadap produksi (Y).

$\mathrm{X} 2, \mathrm{X} 1=$ Variabel peralatan $(\mathrm{X} 2)$, variabel bahan baku (X1) menggambarkan besarnya pengaruh $\mathrm{X} 2$ melalui hubungan $\mathrm{X} 1$ terhadap produksi (Y).

$\mathrm{X} 2, \mathrm{X} 3=$ Variabel peralatan $(\mathrm{X} 2)$, variabel tenaga kerja (X3) menggambarkan besarnya pengaruh $\mathrm{X} 2$ melalui hubungan $\mathrm{X} 3$ terhadap produksi $(\mathrm{Y})$.

$\mathrm{X} 3, \mathrm{X} 1=$ Variabel tenaga kerja $(\mathrm{X} 3)$, variabel bahan baku (X1) menggambarkan besarnya pengaruh $\mathrm{X} 3$ melalui hubungan $\mathrm{X} 1$ terhadap produksi (Y).

$\mathrm{X} 3, \mathrm{X} 2=$ Variabel tenaga kerja (X3), variabel peralatan (X2) menggambarkan besarnya pengaruh $\mathrm{X} 3$ melalui hubungan $\mathrm{X} 2$ terhadap produksi (Y).

\section{HASIL DAN PEMBAHASAN}

\section{Gambaran Produk Keripik Responden}

Kondisi ekonomi biasanya berkaitan dengan usaha atau bidang perindustrian. Usaha perindustrian di Kota Tarakan mengalami peningkatan yang nyata terlihat pada peningkatan jumlah unit usaha industri sebesar 5,09 persen atau meningkat menjadi 578 unit usaha dimana tahun sebelumnya 2014 sejumlah 550 unit usaha. Unit usaha di Kota Tarakan didominasi oleh usaha kecil sebanyak 522 unit usaha atau mencapai 90,31 persen.

Berdasarkan wawancara dengan 15 pemilik UMKM dengan karakteristik rata-rata responden diantaranya berumur 34-42 tahun (53.4 persen), dengan tingkat pendidikan tamatan SMA, pengalaman rata-rata 6-11 tahun. Jenis industry keripik berdasarkan jumlah tenaga kerja digolongkan ke dalam industry mikro sebab ratarata jumlah tenaga kerja para pelaku usaha berkisar antara 1-4 orang sebagaimana menurut UU No.20 Tahun 2008 bahwa usaha dengan jumlah tenaga kerja 1 sampai 4 orang digolongkan ke dalam jenis usaha mikro. Ratarata produksi keripik singkong oleh UMKM adalah sebanyak $90 \mathrm{~kg}$ per bulan.

Produksi keripik singkong menggunakan input-input produksi yang terdiri bahan baku berupa singkong, tenaga kerja dimana rata-rata usaha UMKM mempekerjakan tenaga kerja wanita dengan jumlah tenaga kerja 1 sampai 3 tenaga kerja. Bahan baku dan tenaga kerja dalam penelitian ini digolongkan dalam input variabel. Sedangkan input tetap terdiri dari peralatanperalatan. Jenis peralatan yang digunakan responden mayoritas masih sederhana belum menggunakan peralatan yang modern seperti halnya yang digunakan oleh usaha sekala besar, peralatan yang digunakan meliputi, wajan, kompor, tabung gas, dandang, pisau pemotong keripik, timbanga, siler, dan vacum prayer.

Faktor-Faktor yang mempengaruhi produksi keripik

Faktor-faktor produksi merupakan variabel yang mempengaruhi produksi dan produktivitas. Produksi yang dijelskan oleh variabel (Y) dan faktor produksi yang oleh variabel $(\mathrm{X})$ dianalisis dengan menggunakan analisis jalur. Hasil analisis dengan menggunakan analisis jalur dapat diuraikan sebagai berikut : smirnov

a. Uji normalitas data kolmogorov-

Uji normalitas dimaksudkan untuk menguji nilai residual yang telah di determinasi pada model regresi berdistribusi normal atau 
tidak. Dapat dilihat pada tabel 1 Hasi dari uji normalitas kolmogorov-smirnov sebagai berikut: Tabel 1. Uji Normalitas Kolmogorov-Smirnov Sumber : Data primer yang diolah 2017

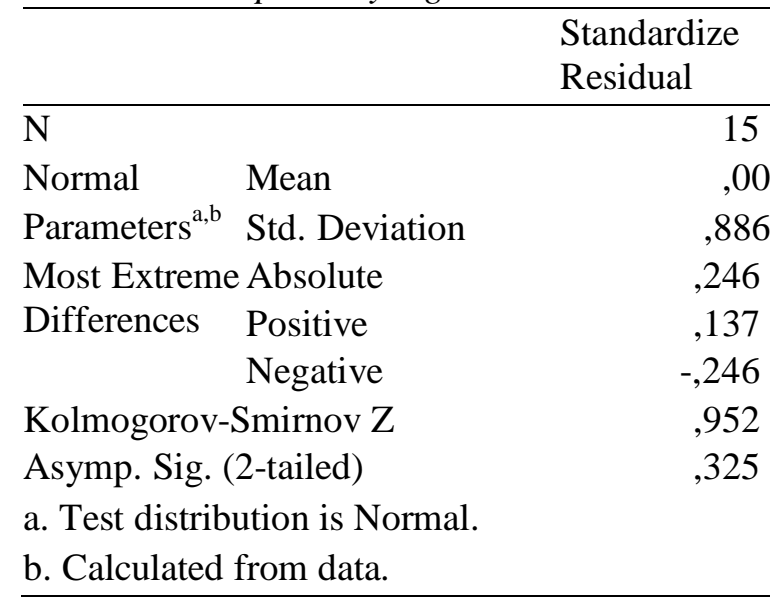

Berdasarkan Tabel 1 dapat dijelaskan bahwa nilai Sig (2-tailed) sebesar 0,325 lebih besar dari 0,05 maka dapat dikatakan bahwa distribusi menyebar secara normal. Dari uji normalitas dapat dikatakan bahwa data penelitian ini menyebar secara normal.

\section{b. Koefisien Jalur}

Dalam korelasi arah dan kuatnya hubungan antara variabel ditunjukan dengan koefisien korelasi. Arah hubungan adalah positif dan negatif sedangkan kuatnya hubungan di tunjukan dengan besar kecilnya angka korelasi. Koefisien korelasi yang mendekati anggka 1 berarti kedua variabel mempunyai hubungan kuat atau sempurna. Perhitungan koefisien jalur dari penelitian ini dapat dilihat pada Tabel 2. Dari Tabel 2. dapat dijelaskan bahwa besarnya hubungan antar variabel dapat dilihat nilai koefisien jalur, nilai dari koefisien jalur medekati angka satu, bahwa dapat disimpulkan bahwa hubungan atara variabel menyatakan kuat dan sangat kuat.
Tabel 2. Nilai Koefisien Jalur

\begin{tabular}{|c|c|c|c|c|c|}
\hline & & $\mathrm{x} 1$ & $\mathrm{x} 2$ & $\mathrm{x} 3$ & Y \\
\hline \multirow{2}{*}{$\mathrm{x} 1$} & Pearson Correlation & 1 &, $665^{* *}$ &, $825^{* *}$ &, $924^{* *}$ \\
\hline & $\begin{array}{l}\text { Sig. (2-tailed) } \\
\mathrm{N}\end{array}$ & 15 & $\begin{array}{l}.007 \\
15\end{array}$ & $\begin{array}{l}.000 \\
15\end{array}$ & $\begin{array}{l}.000 \\
15\end{array}$ \\
\hline \multirow{3}{*}{$\mathrm{x} 2$} & Pearson Correlation &, $665^{* *}$ & 1 &, $865^{* *}$ & $823^{* *}$ \\
\hline & Sig. (2-tailed) &, 007 & & ,000 & ,000 \\
\hline & $\mathrm{N}$ & 15 & 15 & 15 & 15 \\
\hline \multirow{3}{*}{$\mathrm{x} 3$} & Pearson Correlation & $825^{* *}$ & $865^{* *}$ & 1 & $961^{* *}$ \\
\hline & Sig. (2-tailed) & ,000 & ,000 & & ,000 \\
\hline & $\mathrm{N}$ & 15 & 15 & 15 & 15 \\
\hline \multirow{3}{*}{$\mathrm{Y}$} & Pearson Correlation & $924^{* *}$ &, $823^{* *}$ & $961^{* *}$ & 1 \\
\hline & Sig. (2-tailed) & ,000 &, 000 &, 000 & \\
\hline & $\mathrm{N}$ & 15 & 15 & 15 & 15 \\
\hline
\end{tabular}

c. Pengujian Analisis Jalur

Tabel 3. Hasil Regresi Faktor-Faktor

Yang Mempengaruhi Produksi

\begin{tabular}{|c|c|c|c|c|c|}
\hline \multirow{2}{*}{ Model } & \multicolumn{2}{|c|}{$\begin{array}{l}\text { Unstandardized } \\
\text { Coefficients }\end{array}$} & $\begin{array}{l}\text { Standardized } \\
\text { Coefficients }\end{array}$ & \multirow[t]{2}{*}{$\mathbf{t}$} & \multirow[t]{2}{*}{ Sig. } \\
\hline & B & Std. Error & Beta & & \\
\hline Constn & -207486 & 724289,298 & & $-2,865$ &, 015 \\
\hline $\mathrm{x} 1$ & 2,394 & ,460 & ,418 & 5,205 & 001 \\
\hline $\mathrm{x} 2$ & 3,352 & 6,565 & , 046 & ,511 & ,620 \\
\hline $\mathrm{x} 3$ & 37,942 & 7,885 & ,576 & 4,812 &, 000 \\
\hline
\end{tabular}

Dependent Variable: y

Sumber : Data primer yang diolah 2017

Dari Tabel 3 hasil analisis diperoleh (R2) sebesar 0,978 atau 97,8persen artinya kemampuan variabel bebas dalam menjelaskan varian dari variabel terikat adalah sebesar 97,8persen berarti terdapat 2,2persen di jelaskan oleh faktor lain.

Berdasarkan hasil pengolahan data di atas, nilai uji F Sig 0,000 lebih kecil dari 0,05. Hasil tersebut dapat disimpulkan bahwa secara simultan variabel eksogenus berpengaruh terhadap variabel endogenus, sedangkan nilai uji t Sig 0,001 lebih kecil dari 0,05 hasil tersebut dapat disimpulkan bahwa secara individu bahan baku (X1) mempunyai pengaruh yang signifikan terhadap produksi (Y).

Berdasarkan hasil pengolahan data di atas, nilai uji F Sig 0,000 lebih kecil dari 0,05. Hasil tersebut dapat disimpulkan bahwa secara simultan variabel eksogenus berpengaruh terhadap variabel endogenus, sedangkan nilai uji t Sig 0,620 lebih besar dari 0,05 hasil tersebut dapat disimpulkan bahwa secara individu 
peralatan (X2) mempunyai pengaruh yang tidak signifikan terhadap produksi (Y).

Berdasarkan hasil pengolahan data di atas, nilai uji F Sig 0,000 lebih kecil dari 0,05. Hasil tersebut dapat disimpulkan bahwa secara simultan variabel eksogenus berpengaruh terhadap variabel endogenus, sedangkan nilai uji t Sig 0,000 lebih kecil dari 0,05 hasil tersebut dapat disimpulkan bahwa secara individu peralatan (X2) mempunyai pengaruh yang signifikan terhadap produksi (Y).

d. Hasil Analisis Diagram Jalur

Pada Gambar 2. Sudah didapat hasi analisis pengaruh langsung dan nilai dari koefisien jalur. Selanjutnya yaitu menghitung nilai pengaruh langsung dan pengaruh tidak langsung masing-masing variabel bebas (eksogen) $\mathrm{X}$ terhadap variabel terikat (endogen) Y sebagai berikut:

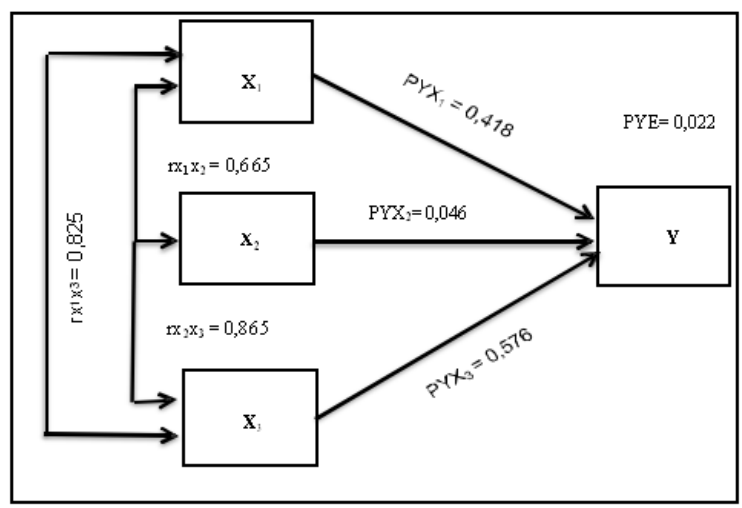

Gambar 2. Hasil Analisis Diagram Jalur

1.Pengaruh Bahan Baku (X1) Terhadap Produksi (Y)

Pengaruh Langsung Bahan Baku (X1) terhadap produksi (Y) yaitu sebesar $0,175(0,418$ $X 0,418$ ) atau sebesar 17,5 persen. Artinya bahwa penambahan bahan baku (X1) akan meningkatkan produksi sebesar 17,5 persen.

Pengaruh Tidak Langsung Bahan Baku (X1) Terhadap Produksi (Y) melalui hubungan Peralatan (X2) sebesar 0,013 $(0,418 \times 0,665 \times$ $0,046)$ atau 1,3 persen. Sedangkan jika melalui hubungan tenaga kerja (X3) besarnya pengaruh tidak langsung adalah $0,199(0,418 \times 0,825 \times$ 0,576 ) atau sebesar 19,9 persen lebih tinggi dibandingkan pengaruh tidak langsung melalui peralatan.

Pengaruh bahan baku (X1) terhadap produksi $(\mathrm{Y})$ total didapat dari akumulasi penjumlahan pengaruh langsung dan pengaruh tidak langsung bahan baku (X1) terhadap produksi (Y), didapat nilai yaitu $0,175+0,013+$ $0,199=0,387$. Berdasarkan perhitungan total pengaruh bahan baku (X1) terhadap produksi (Y) didapat nilai sebesar 0,387 atau 38,7 persen.

2. Pengaruh Peralatan (X2) Terhadap Produksi (Y)

Pengaruh Langsung Peralatan (X2) terhadap produksi (Y) mempunyai kekuatan hubungan yaitu $0.002(0,046 \times 0,046)$ atau sebesar 0,2 persen. Pengaruh Tidak Langsung Peralatan (X2) terhadap Produksi (Y) melalui hubungan bahan baku (X1) yaitu sebesar $0,013(0,046 \times 0,665 \times 0,418)$ atau sebesar 1,3 persen. Sedangkan pengaruh tidak langsung peralatan (X2) melalui hubungan tenaga kerja (X3) yaitu sebesar $0,022(0,046 \times 0,865 \times 0,576)$ atau sebesar 2,2 persen.

Total Pengaruh Peralatan (X2) Terhadap Produksi (Y) Total pengaruh didapat dari akumulasi penjumlahan pengaruh langsung dan pengaruh tidak langsung peralatan (X2) terhadap produksi (Y) yaitu sebesar 0,037 $(0,002+0,013+0,022)$ atau 3,7 persen. 3. Pengaruh Tenaga Kerja (X3) Terhadap Produksi (Y)

Pengaruh Langsung Tenaga Kerja (X2) Terhadap Produksi (Y) yaitu sebesar 0,332 $(0,576 \times 0,576)$ atau 33,2persen. Artinya penambahan satu tenaga kerja akan meningkatkan produksi sebesar 33,2 persen.

Pengaruh Tidak Langsung Tenaga Kerja (X2) Terhadap Produksi (Y)

Melalui Hubungan Bahan Baku (X1), yaitu sebesar $0,199(0,567 \times 0,825 \times 0,418)$ atau 19,9persen. Sedangkan pengaruh tidak langsung melalui hubungan peralatan (X2) yaitu sebesar $0,022(0,576 \times 0,865 \times 0,046) 2,2$ persen.

Total pengaruh tenaga kerja (X3) terhadap produksi (Y) didapat dari akumulasi penjumlahan pengaruh langsung dan pengaruh tidak langsung tenaga kerja (X3) terhadap produksi (Y) yakni sebesar $0,553(0,332+0,199$ $+0,022$ ) atau 55,3 persen.

\section{KESIMPULAN}

Berdasarkan hasil penelitian dan pembahasan diperoleh kesimpulan sebagai berikut:

1.Diperoleh (R2) sebesar 0,978 atau 97,8 persen artinya kemampuan variabel bebas dalam menjelaskan varian dari variabel terikat adalah sebesar 97,8 persen berarti terdapat 2,2 persen di jelaskan oleh faktor lain. Pengaruh bahan baku terhadap produksi sebesar 38,7 persen. Pengaruh peralatan terhadap produksi (Y) sebesar 3,7 persen. Pengaruh tenaga kerja terhadap produksi sebesar 62.2 persen. Pengaruh 
simultan atau secara besamaan bahan baku dan peralatan terhadap produksi dapat dilihat pada nilai koefisien jalurnya yaitu sebesar 55,3 persen.

Faktor yang paling berpengaruh berdasarkan hasil dan pembahasan adalah tenaga kerja, hal ini dilihat dari hasil analisis besarnya pengaruh total tenaga kerja terhadap produksi sebesar 55,3 persen.

\section{DAFTAR PUSTAKA}

Amron. 2009. Analisis Faktor-Faktor yang Berpengaruh Terhadap Produktivitas Tenaga Kerja Outlet Telekomunikasi Seluler Kota Makassar. Jurnal Sekolah Tinggi Ilmu Ekonomi Nobel Indonesia.

Andri. K. 2008. Faktor-Faktor Yang Mempengaruhi Produksi Dan Pendapatan Usaha Mikro Dan Kecil (Studi Kasus Industri Sepatu di Desa Sukaluyu Kecamatan Tamansari Kabupaten Bogor) .[Skripsi]. Jurusan Ekonomi Pertanian Dan Sumberdaya. Fakultas Pertanian . Institut Pertanian Bogor. Bogor.[Indonesia]

Assauri S.2004. Manajemen Produksi dan Operasi. Edisi Revisi.Jakarta:Universitas Indonesia.

Badan Pusat Statistik Kota Tarakan. 2015. Kota Tarakan dalam angka, 2015. Badan Pusat Statistik Kota Tarakan.

Hasan. 2008. Analisis Data Penelitian Statistik. Jakarta: Bumi Aksara

Iryadini. L. 2010.“Analisis Faktor Produksi Industri Kecil Kerupuk

Kabupaten Kendal" Universitas Diponegoro, Semarang

Kurniawan, G. 2010. Analisis Faktor-Faktor yang Mempengaruhi Produktivitas Tenaga Kerja pada PT. Kalimantan Steel (PT. Kalico) Pontianak. Universitas Muhammadiyah Pontianak.

Louis A.2007.Manajemen Produksi dan Operasi.Edisi Revisi. Yogyakarta:Universitas Gajah Mada.

Masiyal. K. 2003. Manajemen produksi dalam perusahaan manufaktur. Rajawali Press. Jakarta.

Muhidin, Sambas Ali dan Abdurahman, Maman. 2007. Analisa Korelasi, Regresi dan Jalur Dalam Penelitian. (Dilengkapi Aplikasi Program SPSS). Bandung : Pustaka Setia.

Nadya. J. 2012. Faktor-Faktor Yang Mempengaruhi Produktivitas Kangkung Air Di Desa Tulo Kecamatan Dolo Kabupaten Donggala Provinsi Sulawesi Selatan. [Skripsi]. Fakultas Pertanian. Universitas Hasanudin.[Indonesia]

Putong. I. 2003. Faktor-Faktor Yang Mempengaruhi Biaya Dan Produtivitas Industri Rumahan Pengolahan Tempe Di Desa Wonolelo, Kecamatan Sawangan,
Kabupaten Magelang. [Skripsi]. Fakultas Pertanian. Universitas Sebelas Maret.[Indonesia]

Sinaga, Resmawati. 2002. Ekonomi Rumah Tangga Pekerja Industri Kecil Tapioka di Tankolot dan Bubulak Desa Ciluar Kota Bogor. [Skripsi]. Jurusan Ilmu-ilmu Sosial Ekonomi Pertanian, Fakultas Pertanian, Institut Pertanian Bogor. [Indonesia]

Suprihono. B. 2003. Faktor-Faktor Yang Mempengaruhi Prodktivitas Dan Pemasar Padi ( Studi Kasus di Kecamatan Karanganyar Kabupaten Demak).[Skripsi] . Universitas Diponegoro. Semarang. [Indonesia]

Yori. A. 2006. Analisis Faktor-Faktor Yang Mempengaruhi Produktivitas Tenaga Kerja Industri Kecil Kerupuk Sinjai Di Kota Bukit Tinggi. [Skripsi]. Jurusan Ekonomi Pertanian Dan Sumberdaya. Fakultas Pertanian . Institut Pertanian Bogor. [Indonesia]. 